\title{
A resolução de problemas no contexto do estágio curricular supervisionado: dificuldades e limites de licenciandos em matemática
}

\author{
Problem solving in the context of curricular supervised training: difficulties and limits \\ of undergraduates in mathematics
}

\author{
Marcelo Carlos de Proença \\ marceloproenca@yahoo.com.br
}

Nelson Antonio Pirola

npirola@,fc.unesp.br

\begin{abstract}
Resumo
O objetivo foi o de investigar as dificuldades e os limites de quatro futuros professores de Matemática para realizar regências de aulas na abordagem da resolução de problemas. Com base na participação em um curso nessa abordagem, os licenciandos elaboraram três sequências didáticas, as quais foram ministradas por meio da atividade de regência de aula da disciplina de Estágio Curricular Supervisionado. Após esse trabalho, participaram de uma entrevista individual para relatar o que tinham desenvolvido nas aulas. Os resultados mostraram dificuldades nos seguintes aspectos: na elaboração das sequências didáticas; em propiciar um ambiente de discussão das estratégias de resolução dos alunos. Além disso, a análise dos dados mostrou limites relacionados: à falta de espaço pelo professor da escola para permitir a realização das aulas elaboradas; à falta de conhecimentos matemáticos básicos dos alunos da escola.
\end{abstract}

Palavras-chave: Licenciatura em Matemática. Resolução de Problemas. Formação inicial. Estágio Curricular Supervisionado. Ensino de Matemática.

\begin{abstract}
The aim was to investigate the difficulties and limits of four future mathematics teachers to conduct classes in regencies approach of problem solving. Based on participation in a course this approach, undergraduates elaborated three didactic sequences, which were taught by the activity of conducting classroom discipline Supervised Curricular Training. After this work, participated in an individual interview to report what had developed in classroom. The results showed difficulties in the following aspects: in the elaboration of didactic sequences; in providing an environment for discussion of resolution strategies students. Furthermore, the data analysis showed limits related: the lack of space at the school teacher to allow implementation of lessons developed; lack of basic mathematical knowledge of the students.
\end{abstract}

Keywords: Degree in Mathematics. Problem Solving. Initial Teacher Education. Supervised Curricular Training. Teaching of Mathematics. 


\section{Introdução}

A investigação apresentada neste artigo é referente a dados provenientes da tese de XXXXX (2012a). Na abordagem da resolução de problemas em sala de aula, entende-se o problema como ponto de partida e não a definição, sendo uma condição importante para abordar e favorecer a formação de conceitos, de procedimentos e de atitudes positivas (BRASIL, 1998). No entanto, o trabalho com a Matemática na escola básica ainda tem se configurado na apresentação de um conteúdo, trabalhando-se suas definições, fórmulas e regras para serem aplicadas, em seguida, em tarefas entendidas, equivocadamente, como problemas (COELHO, 2005; MORELATTI et al., 2010; REDLING, 2011).

As dificuldades no trabalho com a resolução de problemas em sala de aula podem ser decorrentes da falta de uma formação adequada nos cursos de formação inicial de professores de Matemática. Nesse caso, ao ingressarem na escola como professores, acabam perpetuando o mesmo trabalho apontado anteriormente.

Segundo Morelatti et al. (2010), essas dificuldades podem estar relacionadas à constituição de saberes oriundos da formação inicial que não auxiliou a superar, entre outras coisas, experiências prévias provenientes da escola básica e que continuam a interferir nas práticas atuais.

Pesquisas têm mostrado que licenciandos em Matemática apresentaram dificuldades para perceber no enunciado dos problemas as informações completas, incompletas e supérfluas, o que evidencia suas condições para tratar da resolução de problemas (PIROLA, 2000; PIROLA et al., 2006).

Além disso, pesquisas envolvendo propostas de curso/disciplina sobre a resolução de problemas mostraram que os futuros professores apresentaram uma tendência maior para regras e técnicas memorizadas e dificuldades para registrar suas ideias e resolver os problemas propostos (NUNES, 2010; COSTA; ALLEVATO, 2013). Porém, essas pesquisas evidenciaram como pontos positivos a interação, comunicação, diálogos, reflexão e a motivação dos licenciandos na resolução dos problemas, os quais compreenderam que essa abordagem ajuda a desenvolver as atividades em sala de aula.

Tendo em vista os resultados dessas pesquisas, apontadas anteriormente, seria importante uma formação que levasse em consideração, além das discussões sobre a perspectiva da resolução de problemas, o papel do estágio para favorecer experiências concretas de práticas de ensino nessa perspectiva. 
Conforme destacou Imbernón (2001), as práticas devem permitir que os futuros professores reinterpretem e sistematizem as experiências anteriores e presentes, favorecendo o desenvolvimento e a consolidação de um pensamento educativo, baseado na aprendizagem de um conhecimento profissional/pedagógico básico.

Diante dessas considerações, buscou-se, assim, investigar as dificuldades e os limites vivenciados por futuros professores de Matemática na realização de um trabalho baseado na abordagem da resolução de problemas nas atividades de regências de aula que fazem parte da disciplina de Estágio Curricular Supervisionado.

\section{O estágio curricular supervisionado na formação inicial}

A formação inicial de professores é um momento formal de aquisição de conhecimentos, saberes e competências para exercer a profissão do magistério. Nesse sentido, torna-se professor corresponde a um processo complexo que é formado de aprendizagens e experiências provenientes de um percurso formativo (PACHECO; FLORES, 1999).

Nessa formação, é importante capacitar os futuros professores com ações que se apoiem em uma fundamentação válida, evitando o paradoxo de ensinar a não ensinar e evitando que a formação se direcione a uma visão funcionalista, mecânica, rotineira, técnica, burocrática e não reflexiva da profissão (IMBERNÓN, 2001).

Nessa formação, a disciplina de Estágio Curricular Supervisionado corresponde a um espaço importante de realização de atividades que favorece a relação teoria e prática. Desse modo, isso implica em um momento que pode ajudar os licenciandos a articularem os conhecimentos desenvolvidos nas diversas disciplinas da licenciatura e a realidade da sala de aula, buscando promover condições para uma reflexão da prática docente.

No entanto, de acordo com Lopes (2009), é frequente encontrar uma abordagem da teoria como uma função distinta da prática, ou seja, que a teoria é um conjunto independente de ideias e que a prática é algo exclusivo dos estágios curriculares. Para essa autora, os futuros professores precisam ter oportunidades de realizar práticas amparadas por uma reflexão teórica constante. Além disso, destacou que as experiências nos estágios podem ser exemplares para a realização de práticas futuras.

Conforme apontou Moura (2003 apud LOPES, 2009), o estágio é uma preparação anterior à prática profissional. Trata-se de direcionar os futuros professores ao: 
[...] domínio de elementos que têm como meta a sua concretização, o que pressupõe: uma aprendizagem a partir de práticas compartilhadas com os outros; a compreensão do objeto curricular, no sentido de saber lidar com um conhecimento organizado para ensinar alguém sobre o conhecimento instituído; a necessidade de aprendizagem do sujeito que vai ensinar. (MOURA, 2003 apud LOPES, 2009, p. 58).

Essas práticas compartilhadas sugerem a participação do professor da escola nas atividades de estágio. A esse respeito, a legislação destaca que o Estágio Curricular Supervisionado “[...] supõe uma relação pedagógica entre alguém que já é um profissional reconhecido em um ambiente institucional de trabalho e um aluno estagiário”. (BRASIL, 2002, p. 10).

Para Pimenta e Lima (2004), no estágio, é preciso exercer a intencionalidade e a reflexão, o que implica em um processo de formação inicial que favoreça aos futuros professores a apropriação de instrumentos teóricos e metodológicos necessários para compreender a escola no todo.

\footnotetext{
Essa formação tem por objetivo preparar o estagiário para a realização de atividades nas escolas, com os professores nas salas de aula, bem como para o exercício de análise, avaliação e crítica que possibilite a proposição de projetos de intervenção a partir de desafios e dificuldades que a rotina do estágio nas escolas revela. (PIMENTA; LIMA, 2004, p. 102).
}

No entanto, segundo Oliveira (2011), atividades de estágio de observação, participação e regências de aula são, muitas vezes, feitas de forma isolada. De acordo com essa autora, isso é reflexo da falta de parceria entre universidade e escola, entendida como o resultado do descompasso que existe entre leis, projetos pedagógicos dos cursos de licenciatura e estrutura e funcionamento das escolas.

Para Oliveira (2011), nessas atividades, é preciso levar em consideração aspectos como a realização de um diagnóstico, planejamento, investigação e reflexão das atividades propostas, tendo em vista uma formação que conte com a participação dos professores da escola, compartilhando seus saberes e experiências.

Desse modo, por meio das atividades de estágio, é possível propiciar uma formação em que saberes de conhecimentos pedagógicos para ensinar Matemática, de conteúdo matemático, do currículo de Matemática e de experiências de execução de aulas nas escolas (TARDIF, 2007) possam ser devidamente articulados e compreendidos.

Tendo em vista essa formação para ensinar Matemática, o interesse, neste artigo, deu-se pelas ações relacionadas ao trabalho, no estágio, envolvendo a resolução de problemas. 


\section{A resolução de problemas no ensino e na aprendizagem da Matemática}

Um problema de Matemática é aquele em que há um obstáculo entre a proposição e a meta (ECHEVERRÍA, 1998). Isso se configura a partir do momento em que o aluno se depara com uma tarefa de matemática que ele considera difícil de resolver (SCHOENFELD, 1985).

Do ponto de vista cognitivo, se o aluno não conseguir recuperar da memória os conceitos, princípios e procedimentos aprendidos anteriormente, então estará diante de um problema a ser resolvido (CHI; GLASER, 1992; STERNBERG, 2000). Nesse sentido, o aluno precisa:

[...] combinar, na estrutura cognitiva, os conceitos, princípios, procedimentos, técnicas, habilidades e conhecimentos previamente adquiridos que são necessários para encontrar a solução com uma nova situação que demanda uma re-organização conceitual cognitiva. Trata-se, portanto, de uma re-organização dos elementos já presentes na estrutura cognitiva, combinados com os novos elementos trazidos pela nova situação. (BRITO, 2006, p. 19).

Essa reorganização dos conhecimentos previamente adquiridos pode ocorrer, na visão de Echeverría e Pozo (1998), a partir da tomada de decisão do aluno sobre os passos a serem seguidos para resolver um problema. É isso que diferencia um problema de um exercício, pois, “[...] neste último, dispomos e utilizamos mecanismos que nos levam, de forma imediata, à solução". (ECHEVERRÍA; POZO, 1998, p. 16).

Os passos a serem seguidos correspondem a um processo de resolução de problemas que se baseia em etapas/fases. A síntese das etapas/fases propostas por vários autores levou Brito (2006) a discriminar quatro etapas: representação, planejamento, execução e monitoramento.

$\mathrm{Na}$ etapa de representação do problema, o aluno precisa interpretar ou compreender o problema, o que o orienta na recordação de conhecimentos que podem ajudar a obter a solução (CHI; GLASER, 1992). Nesse sentido, é necessário realizar uma representação mental do problema, o que implica no uso de conhecimentos linguístico, semântico e esquemático (MAYER, 1992).

Tais conhecimentos envolvem, respectivamente, a conhecer a língua portuguesa, ou seja, as palavras envolvidas, a conhecer o significado das palavras como, por exemplo, de termos matemáticos e suas relações, a reconhecer, por exemplo, que um determinado problema é um problema de área ou de probabilidade etc., o que mostra que a pessoa tem condições de guiar a atenção e discernir entre dados relevantes e irrelevantes. De modo geral, "essa etapa é crucial para você descobrir a resposta". (STERNBERG, 2000, p. 307). 
Compreendido o problema, o aluno se envolve na etapa de planejamento. Nesta, é preciso utilizar conhecimento estratégico para realizar a busca da solução, ou seja, encontrar um caminho para resolver um problema (MAYER, 1992). Nessa etapa, "você organiza estrategicamente a informação, encontrando uma representação [simbólica] que o habilite da melhor forma para executar sua estratégia.” (STERNBERG, 2000, p. 308).

Estabelecida uma estratégia, o aluno continua o processo de resolução na etapa de execução. O conhecimento necessário é o conhecimento procedimental, o qual envolve realizar corretamente os cálculos matemáticos ou estratégias de cálculo (MAYER, 1992).

Por fim, na etapa de monitoramento, é importante que o aluno avalie a resposta encontrada. Além disso, deve, também, verificar o processo de resolução do problema seguido. Assim, isso permite reconhecer novos problemas, redefinir o problema em questão, enxergar novas estratégias e passar a ter disponíveis novos recursos ou ampliar os existentes (STERNBERG, 2000).

No ensino de Matemática, a análise dessas etapas possibilita observar e analisar o comportamento dos alunos quando estão resolvendo problemas. De acordo com Schroeder e Lester (1989), quando um aluno resolve um problema matemático, temos condições de ter pistas de como ele compreende ou mal entende ou mesmo não entende uma ideia matemática.

Desse modo, a resolução de problemas pode contribuir para o desenvolvimento do pensamento matemático dos alunos (CHARLES, 1985; SCHOENFELD, 1990; MENDES, 2009; FI; DEGNER, 2012). Pode contribuir para ampliar a compreensão de Matemática na medida em que os alunos adquirem capacidades para relacionar uma ideia matemática a uma variedade de contextos, para relacionar um determinado problema a um grande número de ideias matemáticas implícitas nele e para relacionar entre si as ideias matemáticas presentes em um problema (SCHROEDER; LESTER, 1989).

Essa contribuição ajudaria a superar dificuldades e significados equivocados que os alunos constroem, pois o trabalho com a resolução de problemas, em sala de aula, possibilitar-lhes-ia mudar “[...] da visão estreita de que matemática é apenas uma ferramenta para resolver problemas para uma visão mais ampla de que matemática é um caminho de pensar e organizar experiências". (SCHROEDER; LESTER, 1989, p. 39).

Assim, no ensino e na aprendizagem da Matemática, entende-se que o trabalho deve seguir (ou deveria) a abordagem de ensinar via resolução de problemas, a qual sugere que "o ensino 
de um tópico matemático começa com uma situação-problema que expressa aspectos-chave desse tópico [...]." (SCHROEDER; LESTER, 1989, p. 33).

Esse tipo de ensino pode favorecer a aprendizagem dos alunos no que foi descrito anteriormente, uma vez que, primeiro, os alunos precisam reconhecer uma situação como sendo um problema e, assim, se envolverem com o processo de resolução. Desse modo, é possível direcioná-los na construção do novo conceito que se pretende ensinar.

Outras abordagens, porém equivocadas, que podem aparecer no ensino são o ensinar sobre resolução de problemas e ensinar para resolução de problemas (SCHROEDER; LESTER, 1989).

A abordagem de ensinar sobre resolução de problemas se configuraria como uma forma isolada de favorecer a compreensão das relações matemáticas, pois aos alunos são explicitamente ensinadas as etapas de resolução de modo que eles deveriam ter ciência delas quando resolvem problemas. Segundo Schroeder e Lester (1989), isso acontecia para as quatro fases de resolução de problemas do modelo de Polya.

$\mathrm{Na}$ abordagem de ensinar para resolução de problemas, o limite seria o de tratar a resolução de problemas "[...] como uma atividade em que os alunos somente se engajam depois da introdução de um novo conceito ou para seguir uma habilidade de cálculo ou um algoritmo." (SCHROEDER; LESTER, 1989, p. 34, grifo dos autores).

Apesar dos limites dessas duas abordagens, podem ser combinadas e sequenciadas com a abordagem de ensinar via resolução de problemas. Em determinados momentos, os alunos precisam entender, de forma geral, o processo de resolução. Após o tratamento do conteúdo em si, o ensinar para resolução de problemas parece ter sentido apenas quando o objetivo é favorecer as habilidades de cálculo e memorização de técnicas matemáticas pelos alunos, o que corresponderia ao uso de exercícios.

Contudo, esse trabalho com a resolução de problemas implica em introduzir um problema de modo que sejam desafiantes aos alunos e que admitam vários caminhos de resolução, bem como que existam várias soluções possíveis (POZO; ANGÓN, 1998). Implica que os alunos sejam direcionados a tomar as suas próprias decisões sobre os processos de resolução, bem como propiciar uma discussão entre eles sobre seus diferentes pontos de vista (POZO; ANGÓN, 1998). Implica, também, em fazer uma discussão das estratégias de resolução, em lousa, onde os alunos explicitem os caminhos utilizados, resumindo seus resultados, e 
verifiquem se compreenderam o problema e a racionalidade da resposta encontrada (CHARLES, 1985, 1990; BURNS, 1982).

\section{Metodologia}

Para identificar e analisar as dificuldades e limites no ensino de Matemática por meio da abordagem da resolução de problemas na atividade de regência de aula da disciplina de Estágio Curricular Supervisionado, selecionou-se quatro graduandos (L1, L2, L3 e L4, sendo L1 e L2 do gênero feminino e L3 e L4, masculino) do quarto ano de um curso de Licenciatura em Matemática, período noturno, de uma universidade pública do interior do Estado de São Paulo.

Como nessa disciplina os licenciandos podiam realizar as atividades de estágio em escolas públicas de quaisquer cidades, tal seleção ocorreu porque realizariam as atividades de regência de aula na cidade da referida universidade. Desse modo, isso viabilizou o acompanhamento do pesquisador nessas atividades, visando à coleta dos dados.

Assim, este artigo se configura como um estudo de abordagem qualitativa que tem como características, entre outras situações, dados provenientes do ambiente natural onde ocorrem as ações das pessoas, sendo o pesquisador o instrumento principal, o qual busca descrever o processo em que se dão essas ações, de forma indutiva e buscando evidenciar os significados atribuídos pelas pessoas às suas vidas (BOGDAN; BIKLEN, 1994).

Esse ambiente correspondeu à sala de aula da escola pública, onde os participantes tiveram que implementar regências de aulas baseadas na abordagem da resolução de problemas. Para tal, elaboraram três sequências didáticas: uma com um conteúdo de aritmética, uma de álgebra e uma de geometria.

Essa elaboração foi favorecida pela participação dos quatro futuros professores em um Curso sobre Resolução de Problemas, o qual foi desenvolvido e ministrado pelo pesquisador em uma sala de aula da IES no período noturno. Esse curso, composto de oito encontros (30 horas-aula), iniciou-se em março de 2010 e se encerrou em maio desse ano.

Nos primeiro, quarto e quinto encontros, discutiram-se os aspectos teóricos da resolução de problemas (significado do termo problema; etapas de resolução de problemas; o ensino e a aprendizagem baseados na resolução de problemas). O foco principal destacado a ser realizado no ensino foi o ensinar via resolução de problemas, adotando-se o problema como ponto de partida na abordagem de um determinado conteúdo de Matemática. 
Nos segundo, terceiro, sexto e sétimo encontros, resolveram-se 28 problemas, discutindo-se, principalmente, as estratégias de resolução. Em diversos momentos, a resolução desses problemas foi confrontada aos aspectos teóricos do processo de resolução como a compreensão e a avaliação da resposta. Por fim, no oitavo encontro, foi aplicada uma avaliação escrita e individual.

Tendo recebido uma formação sobre a abordagem da resolução de problemas e elaboradas as suas sequências didáticas, os participantes passaram, assim, a implementá-las no contexto da disciplina de Estágio Curricular Supervisionado via regências de aula. Essa implementação se iniciou ao final do primeiro semestre de 2010 e se estendeu até o mês de outubro desse mesmo ano.

Durante esse período, a maioria das aulas ministradas pelos participantes foi observada pelo pesquisador por meio da técnica da observação participante. A observação participante implica na coleta de dados "[...] por meio do contato direto do pesquisador com o fenômeno observado para [...] experienciar e compreender a dinâmica dos atos e eventos, e recolher as informações a partir da compreensão e sentido que os atores atribuem aos seus atos". (CHIZZOTTI, 2001, p. 90).

Além disso, nessa observação, a dinâmica do trabalho realizado em sala de aula foi registrada pelo pesquisador por meio de um instrumento denominado de "roteiro de avaliação de regências de aula" que visava verificar e recolher dados sobre aspectos referentes à abordagem da resolução de problemas. O Quadro 1 mostra os principais itens analisados nas aulas.

\section{Roteiro de avaliação de regências de aula}

1. Introduziu o conteúdo/conceito por meio de um(a):
a. ( ) Problema
b. ( ) Definição
c. ( ) Exercício
d. ( ) Outra Especificar:

2. Discutiu o processo de resolução do problema:

a. ( ) Com os alunos indo até a lousa e registrando suas estratégias de resolução.

b. ( ) Resolvendo somente na lousa e apresentando apenas uma estratégia.

c. ( ) Utilizou somente o que os alunos disseram em voz alta sobre as estratégias.

d. ( ) Outra Especificar:

3. O participante retomou o trabalho com problemas após abordar o conteúdo?
a. ( ) $\operatorname{sim}$
b. ( ) não

4. Outras situações relacionadas ao ambiente de sala de aula como, por exemplo, as dúvidas dos alunos e o comportamento do estagiário.

Quadro 1: Roteiro de avaliação das atividades de estágio. 
A fase final da pesquisa se deu com a realização de uma entrevista individual, áudio-gravada e do tipo semi-dirigida. A entrevista semi-dirigida implica nas seguintes situações: (a) "o entrevistado produz um discurso que não é linear, o que significa que o entrevistador reorienta a entrevista em certos momentos"; (b) "nem todas as intervenções do entrevistador estão previstas antecipadamente. Quando muito este prevê algumas perguntas importantes ou alguns pontos de referência.” (KETELE; ROGIERS, 1993, p. 193).

O objetivo foi o de identificar os argumentos dos licenciandos para explicar se suas aulas ministradas seguiram a abordagem da resolução de problemas. O Quadro 2, abaixo, mostra as questões da entrevista. Além disso, destaca-se que as anotações no "roteiro de avaliação de regências de aula" foram utilizadas como suporte nessa entrevista para uma comparação entre os argumentos dos participantes e o que o pesquisador observou e registrou.

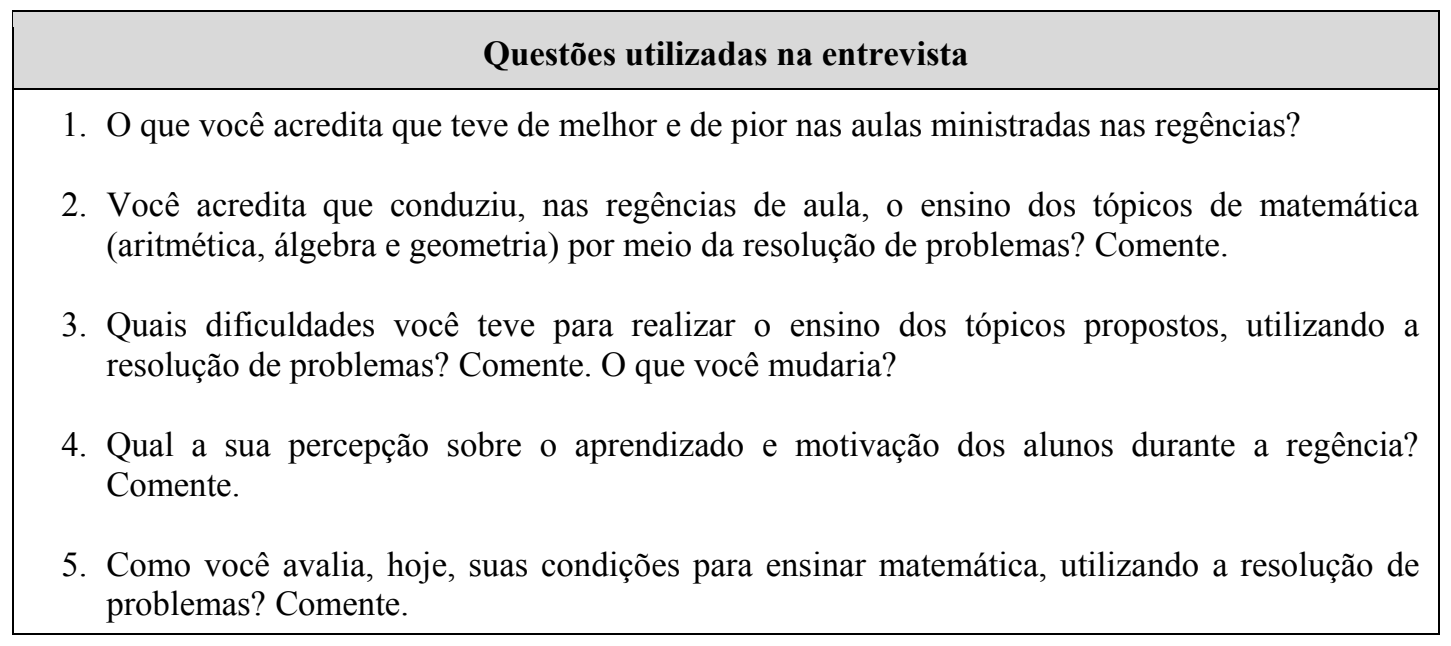

Quadro 2: Questões da entrevista.

Diante da quantidade de dados coletados, oriundos dos registros da observação das regências de aulas dos participantes e das entrevistas, foi necessário a sua organização de modo que permitisse apresentar respostas ao nosso problema de pesquisa (GIL, 1999). Desse modo, a análise dos dados se pautou em três categorias:

- Abordagem de um problema antes de introduzir o conteúdo. Nesta primeira categoria, analisou-se como se deu a abordagem do problema em sala de aula.

- Discussão das estratégias de resolução dos alunos da escola. Nesta categoria, analisou-se a condução do trabalho na perspectiva da resolução de problemas referente à discussão das estratégias desenvolvidas pelos alunos. 
- Participação dos alunos da escola nas aulas. Nesta terceira categoria, analisou-se a participação dos alunos, tendo em vista as aulas ministradas pelos participantes e o que estes identificaram nessa participação.

Tendo em vista a metodologia adotada neste estudo, apresenta-se, em seguida, a análise e a discussão dos dados.

\section{O trabalho realizado no estágio de regência de aula}

As três sequências didáticas - aritmética, álgebra e geometria - foram trabalhadas nas regências de aulas das atividades da disciplina de Estágio Curricular Supervisionado, onde se deveria seguir o ensinar via resolução de problemas. O Quadro 3 mostra os anos escolares, os conteúdos, a duração e o período de acordo com a ordem em que foram abordados na escola.

\begin{tabular}{|c|c|c|c|c|}
\hline Participante & Ano ${ }^{1}$ & Conteúdo $^{2}$ & Duração & Período \\
\hline \multirow{3}{*}{ L1 } & $2^{\circ}$ ano $-\mathrm{EM}-\mathrm{EJA}$ & $\begin{array}{c}\text { Trigonometria - medida } \\
\text { de arcos }\end{array}$ & $6 \mathrm{~h} / \mathrm{a}$ & noite \\
\hline & $2^{\circ}$ ano $-\mathrm{EM}-\mathrm{EJA}$ & Matrizes & $6 \mathrm{~h} / \mathrm{a}$ & noite \\
\hline & $8^{\circ}$ ano $-E F$ & $\begin{array}{l}\text { Grandezas Direta e } \\
\text { Inversamente } \\
\text { Proporcionais }\end{array}$ & $6 \mathrm{~h} / \mathrm{a}$ & manhã \\
\hline \multirow{3}{*}{ L2 } & $9^{\circ}$ ano $-\mathrm{EF}-\mathrm{EJA}$ & Equação $2^{\circ}$ grau & $12 \mathrm{~h} / \mathrm{a}$ & noite \\
\hline & $1^{\circ}$ ano do EM - EJA & $\begin{array}{l}\text { Trigonometria no } \\
\text { triângulo retângulo }\end{array}$ & $12 \mathrm{~h} / \mathrm{a}$ & noite \\
\hline & $6^{\circ}$ ano $-\mathrm{EF}$ & Fração & $6 \mathrm{~h} / \mathrm{a}$ & manhã \\
\hline \multirow{3}{*}{ L3 } & $9^{\circ}$ ano $-\mathrm{EF}$ & Equação do $2^{\circ}$ grau & $6 \mathrm{~h} / \mathrm{a}$ & manhã \\
\hline & $3^{\circ}$ ano - EM - EJA & Geometria Analítica & $6 \mathrm{~h} / \mathrm{a}$ & noite \\
\hline & $6^{\circ}$ ano $-\mathrm{EF}$ & Fração & $6 \mathrm{~h} / \mathrm{a}$ & manhã \\
\hline \multirow{3}{*}{ L4 } & $7^{\circ}$ ano-EF & Potenciação & $6 \mathrm{~h} / \mathrm{a}$ & tarde \\
\hline & $1^{\circ}$ ano - EM & Função do $1^{\circ}$ grau & $12 \mathrm{~h} / \mathrm{a}$ & manhã \\
\hline & $7^{\circ}$ ano $-\mathrm{EF}$ & Simetria & $6 \mathrm{~h} / \mathrm{a}$ & tarde \\
\hline
\end{tabular}

Quadro 3: Conteúdos, ano escolar e duração trabalhados no estágio.

Nas entrevistas, os participantes destacaram suas dificuldades e os limites para trabalhar suas aulas na abordagem da resolução de problemas. Nesse momento, o pesquisador utilizou como

\footnotetext{
${ }^{1}$ EM - Ensino Médio; EF - Ensino Fundamental; EJA - Educação de Jovens e Adultos.

${ }^{2}$ Os conteúdos destacados em cinza correspondem àqueles em que o problema não foi o ponto de partida para abordá-los nas aulas.
} 
apoio as anotações que fez no "roteiro de avaliação de regências de aula". Desse modo, a abordagem desses conteúdos foi analisada tendo em vista os seguintes aspectos, a saber: (i) abordagem de um problema antes de introduzir o conteúdo; (ii) discussão das estratégias de resolução dos alunos da escola; (iii) participação dos alunos da escola nas aulas.

\section{Abordagem de um problema antes de introduzir o conteúdo}

Conforme as informações no Quadro 3, verificou-se, nas entrevistas, que o conteúdo de Grandezas Direta e Inversamente Proporcionais, ministrado por L1, e os conteúdos de Equação de $2^{\circ}$ grau e Fração, ministrados por L2, já tinham sido iniciados pelos professores das turmas que haviam possibilitado a realização do estágio. Porque eles [ $6^{\circ}$ ano] já tinham resolvido exercícios na primeira aula pra introduzir
grandezas pra eles. Ela [professora da escola] tinha feito proporção. (Relato de L1).

A professora já tinha apresentado equação de segundo grau para eles. E em fração a professora já tinha ensinado. (Relato de L2).

Essa situação acabou inviabilizando o ensinar via resolução de problemas, condição que foi prevista na elaboração das sequências didáticas por esses participantes. Em relação ao o participante L3, diferentemente disso, conseguiu introduzir um problema antes de cada um dos três conteúdos ministrados. Porém, no decorrer das aulas sobre Equação de $2^{\circ}$ grau, a professora da turma foi moldando-as conforme já trabalhava.

[...] na oitava série a professora no começo ela disse que não tinha problemas e depois ela foi refinando a minha aula de forma que ela deu, entre aspas, "desse" o que ela daria nesse tempo, entende? Depois da segunda aula, foi só o que ela queria. Ela pediu para que eu trabalhasse só com o livro didático. (Relato de L3).

Um fator que pode ter contribuído para essa situação pode ser decorrente das atitudes dos professores frente ao currículo único de Matemática que se configura, atualmente, nas escolas estaduais do Estado de São Paulo. Nesse currículo, os conteúdos estão definidos para cada bimestre de modo que se um aluno for transferido para outra escola, então não perderá a sequência de estudos. Assim, as atitudes dos professores é justamente não perder ou não se distanciar dos conteúdos trabalhados.

Essa situação acaba interferindo no trabalho a ser desenvolvido pelo licenciando e prejudica a parceria entre escola e universidade (OLIVEIRA, 2011). O estagiário, às vezes, tem interesse em ministrar uma regência de aula interessante sobre um determinado conteúdo, mas acaba 
não podendo executá-la adequadamente, porque se verifica a falta de práticas compartilhadas entre estagiário e professor.

Ao contrário disso, a pesquisa de XXXXXXX (2012b) mostrou a importância da participação dos professores da escola, permitindo a realização das aulas planejadas de quatro licenciandos em Matemática, bem como a avaliação dessas aulas. Essa participação foi fundamental para que esses futuros professores pudessem (re)significar seus saberes docentes mobilizados na prática educativa.

Além dessa situação que envolveu os professores, verificou-se, nas entrevistas, que, na abordagem dos conteúdos de Função de $1^{\circ}$ grau e Simetria, trabalhados por L4, os alunos apresentaram pouca participação, o que o levou a dar outro rumo em suas aulas e até abandonar o trabalho por meio da resolução de problemas.

Então, no primeiro ano eu já desisti depois que eu passei os exercícios. Aritmética [Potenciação] também desestimulou porque lá [1 $1^{\circ}$ ano - EM] só dei um quadrado e eles não quiseram fazer. Eles nem pra redesenhar o quadrado! [já para Simetria] Eu fiz uma atividade assim, mais didática, mas não utilizando resolução de problemas. (Relato de L4).

Verifica-se que mesmo elaborando um trabalho baseado na resolução de problemas que seja interessante e importante para favorecer a aprendizagem da Matemática, os estagiários podem se deparar com a pouca participação e interesse dos alunos da escola.

\section{Discussão das estratégias de resolução dos alunos da escola}

Os participantes L1, L2 e L3 destacaram que, de modo geral, os alunos, tanto regulares quanto da EJA, não queriam vir até a lousa mostrar suas estratégias de resolução. Em relação as suas aulas, L4 destacou: [...] no momento eu nem pensei também de em sala estar fazendo isso. Verifica-se que este relato é resultado, em parte, da pouca participação dos alunos, conforme apontado anteriormente.

Essa atitude dos alunos da escola e de L4 foi constatada pelo pesquisador durante suas observações das aulas. No entanto, essas observações permitiram identificar, apesar de os alunos verbalizarem suas estratégias de resolução, a falta de iniciativa por parte dos próprios futuros professores para propor um caminho de resolução aos alunos, direcionando-os para tal, dando dicas, quando não conseguiram resolver ou quando suas estratégias eram equivocadas, como pode ser exemplificado nos relatos abaixo. 
A conta deles $\left[6^{\circ}\right.$ ano] dava errado quando eles tentavam resolver pelo mesmo método que eles estavam fazendo, aí eu apresentei a regra de três. (Relato de L1).

Mas depois que eu mostrei primeiro, como trabalhava, eles [1 ${ }^{\circ}$ ano EM - EJA] conseguiram resolver os outros dois [problemas de trigonometria], que eram mais ou menos parecidos. (Relato de L2).

Esperava-se que esta situação fosse realizada por parte desses participantes, uma vez que diversas estratégias de resolução foram discutidas no Curso sobre Resolução de Problemas. Segundo os participantes, tiveram dificuldades para encontrar problemas que pudessem ser resolvidos pelas diversas estratégias de resolução quando estavam elaborando as sequências didáticas.

[...] não consegui achar em livros e na internet coisas que eles poderiam resolver por outro caminho a não ser usando seno e cosseno que era o que tinha que passar pra eles. (Relato de L1).

[...] eu tentava encontrar algum problema que tivesse várias estratégias, que os alunos pudessem resolver de várias maneiras. Mas eu tive dificuldades de encontrar esses problemas. (Relato de L2).

[...] eu estava com dificuldades em criar um problema de equação de segundo grau para trabalhar a resolução de problemas e aí [...] explorei isso através do livro didático. (Relato de L3).

Problemas envolvendo conteúdos de trigonometria não foram discutidos no referido curso, o que pode ter sido um fator que contribuiu para que os participantes L1 e L2, que abordaram esses conteúdos em suas regências de aula, não conseguissem encontrar estratégias que não fossem o uso direto de fórmulas.

No entanto, acredita-se que se poderia direcionar os alunos a um caminho específico que os ajudassem a encontrar as respostas dos problemas. Um episódio observado pelo pesquisador dessa dificuldade ocorreu em uma das aulas de L1, onde um dos alunos (EJA) apresentou a resposta correta para a quantidade de graus que se deslocava o ponteiro das horas do relógio quando o ponteiro maior, dos minutos, se deslocava em uma hora, considerando o horário inicial às $12 \mathrm{~h}$. $\mathrm{O}$ caminho utilizado por esse aluno não foi discutido por L1.

No caso do participante L3, a dificuldade destacada anteriormente não era esperada, uma vez que estratégias que poderiam ajudar a incentivar os alunos a resolver equações de $2^{\circ}$ grau sem ser pelo uso da fórmula de bháskara foram discutidas no Curso sobre Resolução Problemas como, por exemplo, a construção de tabelas e a tentativa e erro. 
Talvez, essa dificuldade de L3 pode estar relacionada ao não entendimento das estratégias em si que foram trabalhadas. No entanto, em diversos momentos desse curso, mesmo já tendo discutido determinadas estratégias como, por exemplo, a de "encontrar um padrão", os participantes preferiam utilizar as fórmulas e regras Matemáticas, talvez buscando confirmar a eficácia dessas fórmulas e regras na resolução dos problemas.

Além disso, conforme se verifica nos relatos anteriores, mencionaram tentar encontrar estratégias em livros didáticos. Porém, as diversas estratégias nem sempre constam nesse tipo de material, pois, muitas vezes, não concebe a resolução de problemas como um eixo medular do ensino da Matemática escolar. No âmbito do ensino baseado na resolução de problemas, é necessário que o professor visualize a(s) estratégia(s) que determinado problema pode ser resolvido, o que leva em consideração o seu entendimento da natureza da estratégia.

\section{Participação dos alunos da escola nas aulas}

Os participantes destacaram que a falta de conhecimentos básicos de Matemática dos alunos, principalmente os da EJA, foi o fator que mais contribuiu para prejudicar a tentativa de trabalho baseado na resolução de problemas.

Tinham [EJA] dificuldades com coisas básicas de divisão. Se você colocasse número negativo para eles era coisa de sete cabeças. Então isso foi um impasse. (Relato de L1).

Não sabiam [ $1^{\circ}$ ano EM-EJA] nem o que era ângulo, não sabiam nem o que era altura. [...] eles não conseguiram entender o que estava escrito no problema. Não sabe quanto é dois elevado a dois. Isso aí é complicado. Mesmo conversando em grupo, mesmo eu estando lá tirando dúvidas e tal eles não conseguiam. (Relato de L2).

O problema era, por exemplo, eles [EJA] não saberem o que é três sobre raiz de dois, o que que aquilo representa, o que significa. Esses pré-requisitos, vou dizer entre aspas "bobos", que já deve saber para poder fazer qualquer coisa na matemática eles não sabiam. Mas isso foi o pior, você fica mais frustrado. (Relato de L3).

$\mathrm{Na}$ de aritmética até mostraram interesse pelos problemas, só que não tinham domínio, não sabiam conteúdos, pré-requisitos. E no primeiro ano que eu não gostei é realmente o desinteresse. Eu passei os exercícios... os problemas, e eles nem se importaram no que estavam fazendo e realmente não tinham interesse. A dificuldade mesmo é a falta de pré-requisitos dos alunos. Sem eles é impossível estar trabalhando. (Relato de L4). 
Resultados semelhantes ocorreram na pesquisa de Pereira (2004) que analisou o trabalho em sala de aula desenvolvido com os assuntos divisibilidade e números racionais por meio da resolução de problemas. Nesse estudo, mesmo realizando uma revisão das quatro operações fundamentais e de suas propriedades, alunos que estavam no sexto ano e, em seguida, no sétimo ano do Ensino Fundamental, trabalhando em grupos, tiveram dificuldades para resolver os problemas propostos sem a ajuda da pesquisadora.

Pode-se apontar que a falta de conhecimentos matemáticos básicos dos alunos, bem como a falta de interesse pela aprendizagem, identificados nos relatos dos participantes, estão relacionados ao pouco domínio sobre conhecimentos linguístico, semântico e procedimental (MAYER, 1992). Na visão de Brito (2006), esses alunos tiveram dificuldades em utilizar e combinar conceitos, procedimentos e princípios, aprendidos anteriormente, para tentar encontrar uma solução para os problemas.

No caso específico do participante L4, devido à falta de conhecimentos básicos de Matemática dos alunos, logo no primeiro conteúdo, de Potenciação, destacou:

\begin{abstract}
Mas, daí não deu e eu apresentei o método tradicional ((sorriu)). Lousa, giz e exercício. Quer você queira ou não pelo menos naquele molde eu vi que... pelo menos algumas pessoas da sala vai estar aprendendo. Não é esse o ideal. Porém, é o que temos. (Relato de L4).
\end{abstract}

As observações feitas das aulas de L4 pelo pesquisador o levaram a verificar que isso realmente ocorreu, além do desinteresse de muitos alunos do Ensino Médio na aprendizagem do que foi proposto sobre o conteúdo de função de primeiro grau, conforme o próprio participante mencionou anteriormente. Isso acabou levando esse participante a não seguir a abordagem da resolução de problemas, pois no conteúdo de Simetria, o último ministrado na escola, iniciou-o por meio de uma definição.

Quando eu fui fazer o Plano de Aula [para o conteúdo de Simetria] já falei: vou fazer tradicional com o Caderno do Aluno ${ }^{3}$ do Estado de São Paulo. Porque essas duas [conteúdos de Potenciação e Função] eu vi que não deu certo. (Relato de L4).

De modo geral, essa falta de conhecimentos matemáticos básicos e de interesse por parte dos alunos constitui uma realidade nas escolas públicas e é consequência, entre outros fatores, de uma cultura escolar que ainda tem priorizado o ensino por meio de definições, regras e

\footnotetext{
${ }^{3}$ O Caderno do Aluno foi desenvolvido em 2009, contendo exercícios, mapas, tabelas, indicadores bibliográficos e dicas de estudo para alunos do $6^{\circ}$ ao $9^{\circ}$ anos do Ensino Fundamental e Ensino Médio do Estado de São Paulo, entendido como complemento ao Caderno do Professor. Este, por sua vez, contém os conteúdos a serem trabalhados, de acordo com o bimestre e o ano escolar.
} 
fórmulas para serem aplicados em exercícios que visam à memorização e que pouco favorece uma aprendizagem significativa.

\section{Conclusão}

Neste artigo, o objetivo foi o de investigar as dificuldades e os limites encontrados por quatro futuros professores de Matemática na realização de um trabalho baseado na abordagem da resolução de problemas nas atividades de regências de aula da disciplina de Estágio Curricular Supervisionado.

Os participantes tiveram dificuldades em encontrar problemas que pudessem ser resolvidos por várias estratégias de resolução, relacionadas ao planejamento das sequências didáticas. Tiveram dificuldades, também, durante as regências de aula, em propiciar um ambiente de discussão das estratégias de resolução dos alunos, bem como em direcioná-los a alguma estratégia específica.

Em relação aos limites encontrados para ministrar suas aulas, pode-se destacar que um deles esteve atrelado à abertura e à oportunidade por parte dos professores da escola pública para que os participantes da pesquisa pudessem realizar de forma integral o trabalho que foi planejado. Um aspecto específico foi a não introdução dos problemas em alguns conteúdos porque os professores já haviam iniciado assunto.

Esse limite, geralmente, é entendido como a falta de parceria entre universidade e escola para que se possa contribuir na formação de futuros professores. O relato do participante L3 e a observação do pesquisador mostrou que essa contribuição não foi identificada nas aulas desse licenciando onde a professora permitiu o trabalho do licenciando, porém, durante as aulas, foi moldando-as conforme sua rotina de trabalho.

Outro limite que teve influência negativa nas aulas dos participantes da pesquisa esteve relacionado à falta de conhecimentos matemáticos básicos dos alunos da escola básica e ao desinteresse pela aprendizagem, identificada pelos participantes como falta de autonomia.

Esse limite se constitui como uma realidade educacional e está interligada a uma cultura escolar atual que ainda tem baseado o ensino de Matemática em definições, fórmulas e exercícios. Nessa cultura, essa falta de conhecimentos tem impossibilitado aos professores da escola dar continuidade ao ensino e a aprendizagem de outros conteúdos matemáticos. 
Essas dificuldades e limites foram provenientes de um processo de investigação que teve como base as discussões sobre estratégias de resolução de diversos problemas de matemática e apresentação e discussão da teoria sobre a resolução de problemas no processo ensinoaprendizagem da Matemática, no curso ministrado, para que os participantes pudessem elaborar suas sequências didáticas. Além disso, nesse processo, teve como base para o estudo as experiências vivenciadas nas atividades de regências de aula do estágio, visando propiciar uma análise e reflexões sobre o trabalho desenvolvido na escola.

Contudo, investigações que envolvem a temática da resolução de problemas na Licenciatura em Matemática poderiam incluir a pesquisa de dados relacionados às experiências vivenciadas nas atividades do Estágio Curricular Supervisionado. Nesse sentido, poder-se-ia ter resultados importantes para ajudar a compor um processo de formação inicial que possibilite aos futuros professores de Matemática compreender as dificuldades e limites de sua profissão no trabalho baseado na resolução de problemas.

\section{Referências}

BOGDAN, R.; BIKLEN, S. Investigação Qualitativa em Educação. Uma introdução à teoria e aos métodos. Porto: Porto Editora, 1994.

BRASIL. Ministério da Educação. Parecer CNE/CP 28/2001. Diário Oficial da União, Brasília, 18 jan. 2002. Seção 1, p. 31. Disponível em:

$<$ http://www.uems.br/proe/sec/Parecer\%20CNE-CP\%20028-2001.pdf $>$ Acesso em 05 nov. 2013.

Secretaria de ensino fundamental. Parâmetros Curriculares Nacionais. Brasília: SEF/MEC, 1998.

BRITO, M. R. F. Alguns aspectos teóricos e conceituais da solução de problemas matemáticos. In: BRITO, M. R. F. (Org.). Solução de problemas e a matemática escolar. Campinas, Alínea, 2006. p. 13-53.

BURNS, M. How to teach problem solving. Arithmetic Teacher, v. 29, n. 6, p. 46-49, february, 1982.

CHARLES, R. I. Teacher education and mathematical problem solving: some issues and directions. In: CHARLES, R. I.; SILVER, E. A. (Eds.). The teaching and assessing of mathematical problem solving. Virginia: Lawrence Erlbaum Associates, 1990, NCTM. p. 259-272.

The role of problem solving. Arithmetic teacher, v. 32, p. 48-50, february, 1985. 
CHI, M. T. H.; GLASER, R. A capacidade para a solução de problemas. In: STERNBERG, $R$. As capacidades intelectuais humanas: uma abordagem em processamento de informações. Porto Alegre: Artes Médicas, 1992. p. 249-275.

CHIZZOTTI, A. Pesquisa em ciências humanas e sociais. 5. ed. São Paulo: Cortez, 2001.

COELHO, M. A. V. M. P. A resolução de problemas: da dimensão técnica a uma dimensão problematizadora. 2005. 166f. Dissertação (Mestrado em Educação Matemática) - Universidade Estadual de Campinas, Campinas, 2005.

COSTA, M. S.; ALLEVATO, N. S. G. Resolução de problemas como metodologia de ensino: um caminho para ensinar, aprender e avaliar os conteúdos matemáticos. In: CONGRESO IBEROAMERICANO DE EDUCACIÓN MATEMÁTICA, 7, 2013. Montevidéu - Uruguai. Anais ... Montevidéu: VII CIBEM, 2013.

ECHEVERRÍA, M. P. P.; POZO, J. I. Aprender a resolver problemas e resolver problemas para aprender. In: POZO, J. I. (Org.). A solução de problemas: aprender a resolver, resolver para aprender. Porto Alegre: ArtMed, 1998. p. 13-42.

ECHEVERRÍA, M. P. P. A solução de problemas em matemática. In: POZO, J. I. (Org.). A solução de problemas: aprender a resolver, resolver para aprender. Porto Alegre: ArtMed, 1998. p. 43-65.

FI, C. D.; DEGNER, K. M. Teaching through problem solving. Mathematics Teacher, v.105, n. 6, p. 455-459, february, 2012.

GIL. A. C. Métodos e técnicas de pesquisa social. 5. ed. São Paulo: Atlas, 1999.

IMBERNÓN, F. Formação docente e profissional: formar-se para a mudança e a incerteza. 2. ed. São Paulo: Cortez, 2001.

KETELE, J. M.; ROEGIERS, X. Metodologia da recolha de dados. Coleção Epistemologia e Sociedade. Lisboa: Instituto Piaget, 1993.

LOPES, A. R. L. V. Aprendizagem da docência em matemática: o Clube de Matemática como espaço de formação inicial de professores. Passo Fundo: UPF, 2009.

MAYER, R. E. Thinking, problem solving, cognition. 2. ed. New York: WH Freeman and Company, 1992.

MENDES, I. A. Matemática e investigação em sala de aula: tecendo redes cognitivas na aprendizagem. São Paulo: Livraria da Física, 2009.

MORELATTI, M. R. M. et al. As sequências didáticas descritas por professores de matemática e ciências naturais da rede pública: possíveis padrões e implicações na formação pedagógica de professores. In: ENCONTRO NACIONAL DE DIDÁTICA E PRÁTICA DE ENSINO, 15., 2010, Belo Horizonte. Anais... Belo Horizonte: XV ENDIPE, 2010. CD-ROM.

NUNES, C. B. O Processo Ensino-Aprendizagem-Avaliação de Geometria através da Resolução de Problemas: perspectivas didático-matemáticas na formação inicial de 
professores de matemática. 2010. 430f. Tese (Doutorado em Educação Matemática) Universidade Estadual Paulista, Rio Claro, 2010.

OLIVEIRA, R. G. Estágio curricular supervisionado: horas de parceria escolauniversidade. Jundiaí: Paco, 2011.

PACHECO, J. A.; FLORES, M. A. Formação e avaliação de professores. Porto: Porto Editora, 1999.

PEREIRA, M. O ensino-aprendizagem de matemática através da resolução de problemas no $3^{0}$ ciclo do ensino fundamental. 2004. 263f. Dissertação (Mestrado em Educação Matemática) - Universidade Estadual Paulista, Rio Claro, 2004.

PIMENTA S. G.; LIMA, M. S. L. Estágio e docência. 2. ed. São Paulo: Cortez, 2004.

PIROLA, N. A. Solução de problemas geométricos: dificuldades e perspectivas. 2000. 245f. Tese (Doutorado em Educação Matemática) - Universidade Estadual de Campinas, Campinas, 2000.

PIROLA. N. A. et al. Resolução de problemas com informações supérfluas: uma análise do desempenho de alunos sob a ótica da teoria de Krutetskii. In: SEMINÁRIO INTERNACIONAL DE PESQUISA EM EDUCAÇÃO MATEMÁTICA, 3., 2006, Águas de Lindóia. Anais... Águas de Lindóia: SBEM, 2006. CD-ROM.

POZO, J. I; ANGÓN, Y. M. A solução de problemas como conteúdo procedimental da educação básica. In: POZO, J. I. (Org.). A solução de problemas: aprender a resolver, resolver para aprender. Porto Alegre: ArtMed, 1998. p. 139-165.

XXXXX (2012a)

XXXXX (2012b)

REDLING, J. P. A metodologia de resolução de problemas: concepções e práticas pedagógicas de professores do ensino fundamental. 2011. 166p. Dissertação (Mestrado em Ensino de Ciências e Matemática) - Universidade Estadual Paulista, Bauru, 2011.

SCHOENFELD, A. H. Mathematical problem solving. Orlando: Academic Press, 1985.

SCHROEDER, T. L.; LESTER, F. K., JR. Developing understanding in mathematics via problem solving. In: TRAFTON, P. R.; SHULTE, A. P. (Eds.). New directions for elementary school mathematics. Reston: NCTM, 1989. p. 31-42.

STERNBERG, R. Psicologia cognitiva. Trad. Maria Regina Borges Osório. Porto Alegre: ArtMed, 2000.

TARDIF, M. Saberes docentes e formação profissional. 8. ed. Petrópolis-RJ: Vozes, 2007. 